\title{
Dynamic compressive properties of bovine knee layered tissue
}

\author{
Masahiro Nishida ${ }^{1, \text { a }}$, Yuki Hino ${ }^{1}$, and Mitsugu Todo ${ }^{2}$ \\ ${ }^{1}$ Nagoya Institute of Technology, Gokiso-cho, Showa-ku, Aichi 466-8555, Japan \\ ${ }^{2}$ Kyushu University, 6-1 Kasuga-koen, Kasuga, Fukuoka 816-8580, Japan
}

\begin{abstract}
In Japan, the most common articular disease is knee osteoarthritis. Among many treatment methodologies, tissue engineering and regenerative medicine have recently received a lot of attention. In this field, cells and scaffolds are important, both ex vivo and in vivo. From the viewpoint of effective treatment, in addition to histological features, the compatibility of mechanical properties is also important. In this study, the dynamic and static compressive properties of bovine articular cartilagecancellous bone layered tissue were measured using a universal testing machine and a split Hopkinson pressure bar method. The compressive behaviors of bovine articular cartilage-cancellous bone layered tissue were examined. The effects of strain rate on the maximum stress and the slope of stress-strain curves of the bovine articular cartilage-cancellous bone layered tissue were discussed.
\end{abstract}

\section{Introduction}

In Japan, because of articular diseases, more than one million people go to hospital and $80 \%$ of them are elderly persons. On the other hand, the main reason of elderly persons for needing long-term care is articular diseases in Japan. The most common articular disease is knee osteoarthritis (degenerative arthritis). The knee osteoarthritis is defined as a degenerative change of bones based on the progressive degenerative lesion of articular cartilage [1]. The articular cartilage consists of hyaline cartilage, surrounds articular surfaces and is translucent white. The main functions of articular cartilage are energy absorption, stress redistribution and lubrication. In general, articular cartilage is worn down by advancing age, obesity and muscle deterioration. In the early stage of the knee osteoarthritis, conservative therapy is effective; heat-retention and knee supporter in the case of mild symptoms, and antiphlogistic analgetic and injection of hyaluronan drug under a painful condition. In the case of joint degeneration after symptom progression, operative therapy such as high tibial osteotomy (HTO) is provided. For patients of further joint degeneration, total knee arthroplasty (artificial joint replacement surgery) is usually performed [2].

Artificial joints have been widely used and their parts are made of metals such as titanium alloys and cobalt chrome alloys, ultrahigh molecular weight polyethylene (UHMWPE) and ceramics such as alumina, zirconia and hydroxyapatite. Therefore, when artificial joints are used for long time, contact surfaces are always worn down and revision surgery are usually needed. Recently, the tissue engineering and regenerative medicine have received a lot of attention. In the field of tissue engineering and regenerative medicine, cells and scaffolds which are artificial structures supporting tissue formation are

\footnotetext{
${ }^{a}$ Corresponding author: nishida.masahiro@nitech.ac.jp
}

important both ex vivo as well as in vivo. From the view point of effective treatment, in addition to histological feature, compatibility of mechanical properties is also important.

Several studies have been conducted on static and dynamic mechanical properties of body tissues near knee joints. Kobayashi et al. measured static and dynamic compressive properties of bovine cancellous bones using universal testing machine and Hopkinson pressure bar method and reported that elastic modulus and yield stress increased with density and strain rate [3]. Shimizu et al. measured static and dynamic compressive properties of porcine patellar cartilages using universal testing machine and Hopkinson pressure bar method and the mechanical properties were compared with those of double network gels for artificial articular cartilage [4]. Parish et al. studied dynamic tensile behavior of porcine cortical bones [5]. Laporte et al. [6] and Prot et al. [7] examined dynamic behavior and microstructure of bovine cancellous bone. They have focused on mechanical properties of each tissue.

However, because body tissues are always layered structures, mechanical properties of layered structures are essential. Hwang and Todo [8] studied static compressive properties of layered structures. In this study, dynamic and static compressive properties of bovine articular cartilagecancellous bone layered tissue were measured.

\section{Experimental methods}

A part of knee joint of bovine thigh bone was used as specimens. Figure 1 shows a photograph of the crosssectional surface of the distal end of femoral bone (external and internal condyles) which is upper side of knee joint. The surface of the distal end of femoral bone is surrounded by the white cartilage tissue and red cancellous bone is observed on the inner side of femoral bone.

This is an Open Access article distributed under the terms of the Creative Commons Attribution License 4.0, which permits unrestricted use, distribution, and reproduction in any medium, provided the original work is properly cited. 


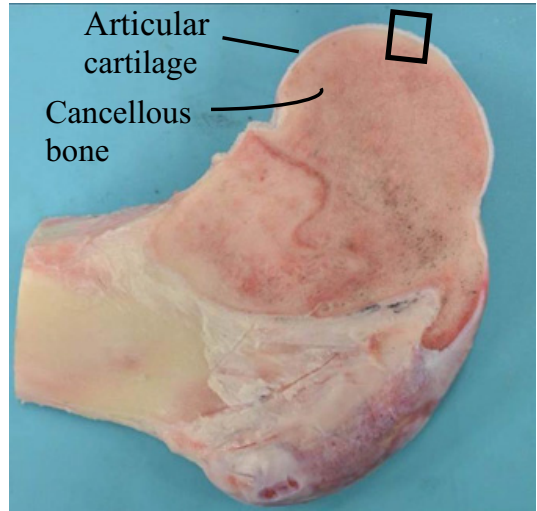

Figure 1. Photograph of distal end of femoral bone (Upper side of knee joint).

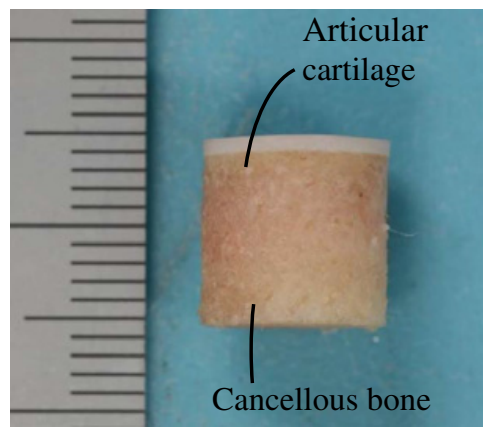

Figure 2. Compressive test specimen.

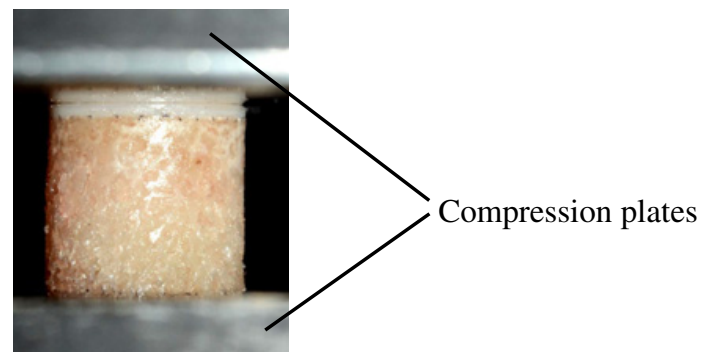

Figure 3. Photograph of specimen during compression test.

Articular cartilage-cancellous bone layered tissue indicated by the black quadrangle part in Fig. 1 was cut out by machining. Compressive test specimens with a diameter of $10 \mathrm{~mm}$ and a height of $10 \mathrm{~mm}$ were made as shown in Fig. 2. The averaged thickness of four points for articular cartilage was $0.87 \mathrm{~mm}$.

Quasi-static compressive tests were conducted at a crosshead speed of $0.05 \mathrm{~mm} / \mathrm{min}$ (strain rate of $8.3 \times 10^{-5} \mathrm{~s}^{-1}$ ) using a universal testing machine. The displacement of compression plates was measured by displacement transducer (Kyowa Electronic Instruments Co., Ltd., DTH-A-30). Each strain of articular cartilage and cancellous bone was measured by image analysis of photographs during quasi-static compressive tests, using ImageJ. Figure 3 shows a photograph of specimen during quasi-static compressive tests.

At high strain rates over $100 \mathrm{~s}^{-1}$, the stress-strain curves were measured by the split Hopkinson pressure bar (Kolsky bar) method, as shown in Fig. 4. The

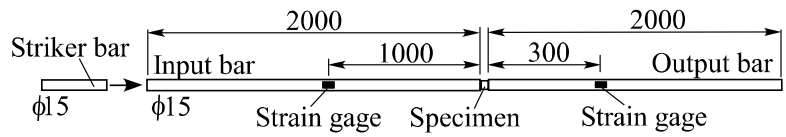

Figure 4. Split Hopkinson pressure bar (Kolsky bar) method.

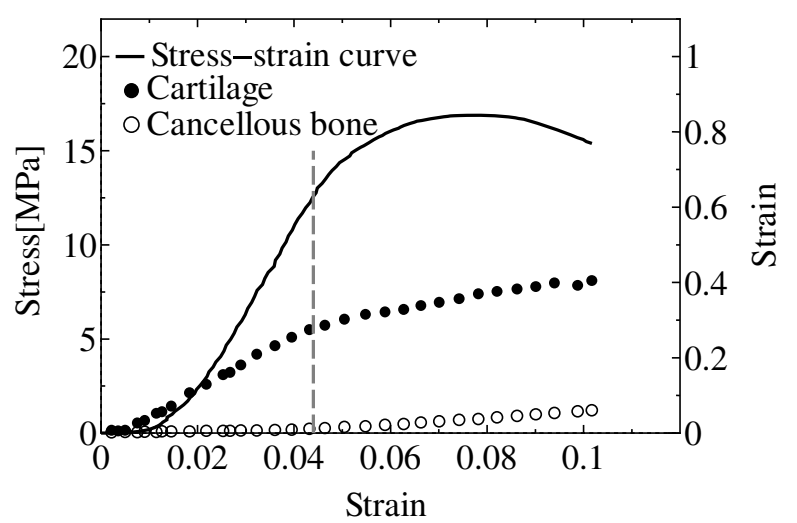

Figure 5. Stress-strain curve of specimen and each strain of cartilage and cancellous bone.

Table 1. Material constants of input and output bars used in calculation.

\begin{tabular}{|c|c|c|}
\hline Density & $\begin{array}{c}\text { Elastic wave } \\
\text { velocity in bar }\end{array}$ & $\begin{array}{c}\text { Young's } \\
\text { modulus } E\end{array}$ \\
\hline $2.81 \times 10^{3} \mathrm{~kg} / \mathrm{m}^{3}$ & $5150 \mathrm{~m} / \mathrm{s}$ & $71.7 \mathrm{GPa}$ \\
\hline
\end{tabular}

input and output bars were made of an aluminum alloy (7075-T6511), and they had a diameter of $15 \mathrm{~mm}$ and respective lengths of $2000 \mathrm{~mm}$ and $1300 \mathrm{~mm}$. Strain gages were placed on the input and output bars at distances of $1000 \mathrm{~mm}$ and $300 \mathrm{~mm}$ away from the specimen, respectively. When the stress histories were almost equal on both sides of the specimens, the stress and strain of the specimens can be calculated from the strain on the bars using Eqs. (1) and (2) $[9,10]$.

$$
\begin{gathered}
\sigma(t)=\frac{A E}{A_{S}} \varepsilon_{T}(t) \\
\varepsilon(t)=\frac{2 c_{3}}{L} \int_{0}^{t}\left[\varepsilon_{I}(t)-\varepsilon_{T}(t)\right] d t .
\end{gathered}
$$

Here, $\varepsilon_{I}$ and $\varepsilon_{T}$ denote the axial strain in the input bar induced by the incident wave and the axial strain in the output bar induced by the transmitted wave, respectively. $E$ and $c_{3}$ denote the Young's modulus and elastic wave velocity of the input and output bars, respectively. $L$ denotes the specimen thickness. $A$ and $A_{s}$ denote the crosssectional areas of the input/output bars and the specimens. The material constants of the aluminum alloy (7075T6511) bars used in the calculations are shown in Table 1. The strikers with a diameter of $15 \mathrm{~mm}$ and lengths of $490 \mathrm{~mm}$ made of aluminum alloy (7075-T6511) were used.

\section{Results and discussion}

Figure 5 shows static stress-strain curves. The right axis shows each strain of articular cartilage, black circles, and cancellous bone, white circles, as a function of specimen 


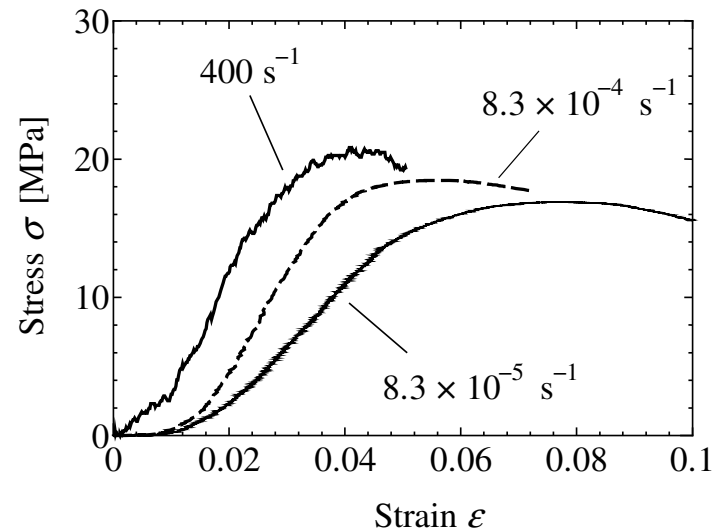

Figure 6. Stress-strain curve of specimens at high and low strain rate.

strain on the horizontal axis. Each strain of articular cartilage and cancellous bone was measured by image analysis. The stress-strain curves were divided into two stages. In the early stage until strain of 0.04 , the stress of specimen increased with strain on the horizontal axis and the strain of articular cartilage also increased as shown by black circles. However the strain of cancellous bone was very small as shown by white circles. At the strain of 0.04 , the increase rate of the strain of articular cartilage lessened as shown by black circles and the strain of cancellous bone started to increase as shown by white circles.

Until the strain of 0.04 , the slope of stress-strain curve continuously increased and, when cancellous bone began to increase, the slope of stress-strain curve started to decrease. At the specimen strain of 0.075 , the stressstrain curves showed a peak and the stress at the peak (the maximum stress) was approximately $17 \mathrm{MPa}$.

Laporte et al. reported that the maximum stress of bovine cancellous bones was approximately $8 \mathrm{MPa}$ and the strain showing the maximum stress was 0.05 in the static compression tests [5]. Kobayashi et al. reported that the maximum stress of bovine cancellous bones was approximately $25 \mathrm{MPa}$ and the strain showing the maximum stress was 0.04 . Our results of articular cartilage-cancellous bone layered tissues showed that the maximum stress was $17 \mathrm{MPa}$ and the strain of only cancellous bones (right axis) at the maximum stress was 0.032. Those values were similar to the results of Laporte et al. and Kobayashi et al. It is assumed that the main reason for the different is an individual difference in bones.

As a result, the stress-strain curves of articular cartilage-cancellous bone layered tissues were roughly divided into two regions. In the first part, the articular cartilage mainly deformed and the cancellous bone seldom deformed. In the next part that the deformation of specimens progressed and the stress of specimens approached to the failure stress of cancellous bone, the deformation of articular cartilage and the fracture of cancellous bone occurred simultaneously. Because the slope of stress-strain curves decreased when the cancellous bone started to deform, the fracture of cancellous bones progressed just after the onset of deformation.

Compressive tests were also conducted at a crosshead speed of $0.5 \mathrm{~mm} / \mathrm{min}$ ( strain rate of $8.3 \times 10^{-4} \mathrm{~s}^{-1}$ ) using a universal testing machine. Results using a universal testing machine were compared with results of SPPB. Figure 6 shows the effects of strain rate on stress-strain curves. The strain rate slightly increased the maximum stress and clearly increased the initial slope of stress-strain curves. It seems that the viscoelastic behavior of articular cartilage and/or cancellous bone increased the slope.

\section{Conclusions}

The dynamic and static compressive properties of bovine articular cartilage-cancellous bone layered tissue were measured using a universal testing machine and a split Hopkinson pressure bar method. The stress-strain curves of articular cartilage-cancellous bone layered tissue were roughly divided into two stages at low strain rate. The strain rate slightly increased the maximum stress and clearly increased the initial slope of stress-strain curves.

The authors are greatly indebted to Professor Tadashi Inaba and Professor Yuichi Kasai of Mie University for their valuable advice with respect to the split Hopkinson bar. The authors are also greatly indebted to Mr. Masayuki Hayashi, an assistant researcher of Nagoya Institute of Technology, for his help with the experimental work.

\section{References}

[1] Y. Tachibana, Physical Therapy Science, 20, 235 (2005) (In Japanese)

[2] T. Suzuki, Y. Hayashi, Bone Encyclopedia, Asakura Publishing, 409 (2003) (In Japanese)

[3] K. Kobayashi, Y. Tanabe and T. Hara, Transactions of the Japan Society of Mechanical Engineers, Series A, 63, 160 (1997) (In Japanese)

[4] D. Shimizu, H. Fujiki, M. Daimaruya, O. Shiozaki, Proc. 47th JSME Hokkaido branch conference, 109 (2008)

[5] A. Parish, W. Chen and T. Weerasooriya, Proc. DYMAT 2009, 2, 917 (2009)

[6] S. Laporte, F. David, V. Bousson and S. Pattofatto, Proc. DYMAT 2009, 2, 895 (2009)

[7] M. Prot, T.J. Cloete and S. Pattofatto, EPJ Web of Conference, 26, 03003 (2012)

[8] S. Hwang and M. Todo, Journal of Solid Mechanics and Materials Engineering, 7, 293 (2013)

[9] G.T. Gray, III, ASM Handbook Vol. 8, Mechanical Testing and Evaluation, ASM 462 (2000)

[10] W. Chen, B. Song, Split Hopkinson (Kolsky) Bar: Design, Testing and Applications, Springer, (2010) 